\title{
UM OlHAR SOBRe O ENSINO DE Sociologia: Pesquisa e Ensino
}

\author{
Cassiana Tiemi Tedesco Takagi ${ }^{1}$ \\ Amaury Cesar Moraes ${ }^{2}$
}

\begin{abstract}
Resumo
0 objetivo deste artigo é discutir o ensino de Sociologia a partir da produção acadêmica e do ensino na escola média. Para tanto, analisamos algumas publicações sobre o assunto relacionando às condições de trabalho fornecidas pela rede estadual de ensino na cidade de São Paulo.

Palavras-chave: Ensino de Sociologia. Educação. Nível médio e docência.
\end{abstract}

\section{Abstract}

The goal of this article is to discuss Sociology teaching evaluating academic prodution associated across the high school teaching. In order to do this, we compared some published articles related to this subject to the real work conditions in the state public network schools in São Paulo city.

Key words: Sociology Teaching. Education. the High School.

\section{INTRODUÇÃO}

0 ensino de Sociologiaé uma temática pouco explorada, especialmente no contexto acadêmico, uma vez que são poucos os estudos desenvolvidos nessa área, resultando disso que os conhecimentos sobre o ensino de Sociologia são bastante limitados. Isso se explicaria por uma hierarquização entre os campos acadêmico, científico e escolar nas ciências sociais, dado que o ensino ocupa uma posição de pouco prestígio diante dos demais campos. Conforme assinala Ileizi Silva (2003, p.3):

0 tema 'ensino de sociologia' não tem sido objeto de muitas pesquisas seja nos cursos de pós-graduação em Educação, seja nos cursos de Ciências Sociais. Certamente, uma das razões para isso é o fato dessa disciplina não figurar sempre nos currículos das escolas de ensino médio.

\footnotetext{
${ }^{1}$ Mestre em Sociologia da Educação pela Faculdade de Educação - Universidade de São Paulo

${ }^{2}$ Professor Doutor do Departamento de Metodologia do Ensino e Educação Comparada - Faculdade de Educação - Universidade de São Paulo.
} 
As condições da disciplina indicam que dentro do campo das Ciências Humanas, o ensino de Sociologia não encontra espaço para discussão por estar em situação subalterna. Esta disciplina ocupa tal posição em relação às demais disciplinas escolares, talvez por ainda não estar com um espaço de discussão consolidado, seja no universo acadêmico seja no universo escolar, formando um círculo vicioso no qual a ausência de um implica à ausência do outro.

Segundo Moraes (2004, p. 5),

Observe-se, antes de tudo, que enquanto nas outras comunidades foi havendo um "reencontro"entre "pesquisadores-professores" e "professores", isto é, entre professores universitários e professores da educação básica, (...) entre os cientistas sociais, a tendência tem sido de separação: pesquisadores em ciências sociais - que raramente se identificam como professores, mesmo que universitários -, e professores de sociologia do ensino médio estão em mundos diversos: aqueles bem postos, legitimados no âmbito acadêmico; estes, desgarrados, vivendo uma ambiguidade crônica: entre 0 sindicato dos professores, que não lhes dá suporte em sua especificidade como "professores de sociologia" - dado que o sindicato deve abstrair o que não é ser professor - e o sindicato dos sociólogos, que não lhes pode reconhecer essa outra especificidade "professor"- dado que isso subtrai a identidade do sociólogo

De acordo com Moraes, nem a Sociologia encontrou um espaço legítimo como disciplina nem os professores da escola básica são atendidos em sua especificidade ao ministrarem esta disciplina. Enquanto outras disciplinas debatem junto com os pesquisadores novas estratégias de ensino, nas Ciências Sociais não há espaço para o ensino.

No passado, a legitimação do pensamento sociológico no Brasil esteve associada à sua difusão nos ambientes de formação em nível escolar básico, porque a inserção da Sociologia enquanto disciplina teve um papel fundamental nas reflexões sobre 0 desenvolvimento desta ciência no país. Como discutiu Florestan Fernandes (1985, p.46) sobre a introdução de Sociologia na escola secundária,

[...] Os interesses alimentam a presunção de que seria uma medida praticamente importante e desejável a introdução da sociologia no currículo da escola secundária. Admite-se que as oportunidades docentes concedidas aos licenciados em ciências sociais são demasiado restritas. A ampliação do sistema de matérias do ensino secundário permitiria garantir uma absorção regular ou permanente dos licenciados nesse setor e garantiria às secções de Ciências Sociais nas Faculdades de Filosofia uma certa equivalência com as demais secções, no que concerne à motivação material dos alunos, que procuram essas Faculdades porque pretendem dedicar-se 
ao exercício do magistério secundário e normal. Tais interesses são naturalmente legítimos. Nas condições brasileiras, é quase impossível estimular o progresso das pesquisas sociológicas sem que se criem perspectivas de aproveitamento real da mãode-obra especializada".

Fernandes discutira a introdução de Sociologia na escola secundária como uma medida para a absorção dos novos docentes licenciados em Ciências Sociais, na década de 1950, pois era sabido que as possibilidades profissionais do estudante desta área eram restritas e a partir da institucionalização da Sociologia na escola secundária, os alunos poderiam dedicar-se ao magistério, e Florestan acreditava que tal garantia atrairia mais estudantes. Um aumento do número de estudantes poderia refletir sobre o aumento no volume de pesquisas, já que haveria uma expectativa real de empregabilidade, mesmo que ela não se concretizasse para todos, pois somente alguns seriam pesquisadores. Sem tal expectativa, no entanto, o desenvolvimento de pesquisas científicas também seria prejudicado, o curso passaria a ser desprestigiado e ao longo do tempo o número de ingressantes passaria a diminuir, chegando ao ponto que não houvesse número de pessoas suficiente para produzir pesquisas nem para reproduzir a própria estrutura acadêmica universitária - professores para a própria faculdade. Se o curso não oferece perspectivas profissionais, há uma tendência para a diminuição do número de ingressantes e/ou evasão, conseqüientemente um esvaziamento do universo de pesquisas.

De acordo com Ileizi Silva (2002, p.2), a institucionalização da disciplina auxilia no desenvolvimento do pensamento sociológico no Brasil e na ampliação do campo sociológico científico:

Acredita-se que a consolidação do pensamento sociológico no Brasil deveria estar associada também à sua difusão nos ambientes de formação de nível escolar básico. Ou seja, a inserção da Sociologia, enquanto disciplina importante na hierarquia das disciplinas escolares deveria ser um problema fundamental nas reflexões sobre 0 desenvolvimento desta ciência no país. É a partir da difusão dos conhecimentos nas escolas, que se pode permitir que a sociedade valorize as diferentes ciências (Chervel, 1988). Assim, refletir a reinstitucionalização da Sociologia nos Currículos das Escolas Secundárias, articula-se ao esforço de reflexão sobre o desenvolvimento do pensamento sociológico no Brasil.

Segundo Ileizi Silva, o pensamento sociológico deveria discutir o modo como sua produção acadêmica é difundida no universo escolar; a partir disso, a autora propõe que as condições de ensino de Sociologia sejam postas em discussão, ou seja, que o ensino de Sociologia esteja na pauta das discussões acadêmicas brasileiras. Mesmo que as escolas 
não produzam conhecimentos acadêmicos, elas poderiam contribuir na ampliação da discussão, assim como, a produção acadêmica poderia auxiliar no processo de reinstitucionalização da disciplina, ao ampliar tal discussão para além das unidades escolares.

A partir do texto de Ileizi Silva, é possível compreender que há uma separação entre o ensino e a ciência, dado que o ensino ainda é discutido em um número reduzido de pesquisas, sendo considerado uma área de menor prestígio nos estudos sociológicos. Tal separação acarreta prejuízos tanto na área educacional, que não acompanha a produção científica de maneira satisfatória, quanto no campo científico que poderia se desenvolver mais se incorporasse questões educacionais.

A separação da Sociologia - entre ensino e pesquisa - vem prejudicando o seu desenvolvimento no Brasil, porque ainda há forte insistência na manutenção dessa divisão, ou seja, os cientistas ainda persistem na dissociação do ensino em relação ao ramo científico, o ensino de Sociologia está dissociado das discussões científicas porque a educação não é considerada como um ramo da ciência, ao afirmarem que a educação não pode ser um objeto científico de 'excelência', da mesma forma que Bourdieu discutira durante 0 início de sua carreira,

Quando comecei a me interessar pela sociologia da educação, era a disciplina mais fraca da sociologia. Era um setor dominado, em todos os países. Estava ligada aos professores primários, às mulheres, em suma, tinha todas as características de uma disciplina dominada e muito fraca. Fraca do ponto de vista social mas, infelizmente, também sob o aspecto intelectual (LUDKE, 1991, p. 7).

Apesar de Bourdieu, um intelectual muito reconhecido no campo, ter trazido contribuições para a área, os temas educacionais continuam a apresentar pouco prestígio diante dos demais ramos científicos da Sociologia.

Um outro entrave para a ampliação da discussão em torno do ensino de Sociologia seria um privilegiamento de algumas disciplinas do ensino médio em detrimento de outras, porque a constituição de um currículo mínimo não contemplaria disciplinas de menor prestígio, como Filosofia, Sociologia e Psicologia, e quando estas foram cogitadas estavam inseridas no contexto de um "enriquecimento pedagógico", apenas como um complemento para a formação do educando, mas que não teriam valor em si mesmas, embora se saiba que:

[...] filosofia, sociologia e psicologia têm o mesmo status epistemológico das outras disciplinas escolares, com especificidades tais não podem ser recobertas por outras disciplinas, mantêm interfaces com quaisquer outras disciplinas do currículo de 
modo que são essenciais para manter uma força crítica que renove os próprios currículos escolares" (MORAES, 2002, p. 5).

Ao discutir esta problemática, Moraes afirma que a Sociologia não deveria entrar no currículo por uma razão de "enriquecimento pedagógico", uma vez que a disciplina apresenta uma proposta de ensino com o mesmo estatuto das demais disciplinas, não compreendo-na como uma área de conhecimento secundária.

A atual grade curricular do ensino médio atribui maior valor, oferecendo maior número de aulas, às disciplinas tidas como fundamentais, como Língua Portuguesa e Matemática cada uma contando com seis aulas semanais na rede estadual de ensino de São Paulo, cabendo às demais dividir o restante das aulas. Sendo assim, a Sociologia parece ser uma disciplina de menor prestígio por dois motivos: porque éparte das ciências humanas, parece não ter objeto próprio e por ser considerada um conhecimento extra, não deveria estar na grade curricular comum e sim contemplada na parte diversificada.

De acordo com as Diretrizes Curriculares Nacionais do Ensino Médio, temos

Nesta área (Ciências Humanas) incluir-se-ão também os estudos de Filosofia e Sociologia necessários ao exercício da cidadania, para cumprimento do que manda a letra da lei. No entanto, é indispensável lembrar que espírito da LDB é muito mais generoso com a constituição da cidadania e não confina a nenhuma disciplina específica, como poderia dar a entender uma interpretação literal da recomendação do inciso III do Parágrafo primeiro do artigo 3633. Neste sentido, todos os conteúdos curriculares desta área, embora não exclusivamente dela, deverão contribuir para a constituição da identidade dos alunos e para o desenvolvimento de um protagonismo social solidário, responsável e pautado na igualdade política. (MORAES, 2002, p. 2).

Segundo este Parecer (CNE/ CEB 15/ 1998), os conteúdos da Sociologia poderiam ser tratados por outras disciplinas, pois ainda que atribuam um valor (exercício da cidadania) ao ensino dessa disciplina, acreditam que seus temas possam ser tratados de modo interdisciplinar. Perante isso, a questão da interdisciplinaridade passa a figurar nos debates acerca do ensino de Sociologia. Visto que em decorrência disso, surgiu aquela idéia de 'enriquecimento pedagógico', como se os seus conteúdos fossem um 'verniz', um complemento na formação do educando. Se elaé compreendida como conhecimento adicional, seus conteúdos poderiam ser oferecidos em outras disciplinas, não havendo necessidade para a existência de uma disciplina específica.

\footnotetext{
3 " $§ 1^{0}$ Os conteúdos, as metodologias e as formas de avaliação serão organizadas de tal forma que o final de ensino médio o educando demonstre: III - domínio dos conhecimentos de Filosofia e de Sociologia necessários ao exercício da cidadania" (LDB 9394/ 96, art. 36, § 1², III apud MORAES, 2003b, p. 2)
} 
A discussão em torno do currículo ocorre em dois níveis: geral e específico, o primeiro diz respeito ao currículo do ensino médio por discutir o currículo de modo amplo e o segundo, à disciplina Sociologia. Consideramos importante 0 aspecto geral por estarmos discutindo a presença da Sociologia no currículo.

Por esta razão, recorremos a Tomaz Tadeu da Silva ao analisar as várias teorias curriculares historicamente organizadas, discutindo as implicações da seleção destas teorias para a constituição da identidade do educando; em outras palavras, cada uma das teorias foi elaborada para formar um tipo de aluno, mesmo que a intenção não fosse claramente exteriorizada, o currículo é expressão de objetivos específicos de formação. 0 tipo de conhecimento selecionado é intencional, mesmo que em algumas teorias não fique evidente, certamente expressam um tipo de leitura da realidade. Como é possível observar no seguinte trecho de Tomaz Tadeu da Silva (2004, p. 16):

É precisamente a questão do poder que vai separar as teorias tradicionais das teorias críticas e pós-críticas do currículo. As teorias tradicionais pretendem ser apenas isso: "teorias" neutras, científicas, desinteressadas. As teorias críticas e as teorias póscríticas, em contraste, argumentam que nenhuma teoria é neutra, científica ou desinteressada, mas que está inevitavelmente, implicada em relações de poder [...].

De acordo com Tomaz Tadeu da Silva, as teorias tradicionais tinham a pretensão de neutralidade e cientificidade, camuflando as reais intenções curriculares. Enquanto as teorias atuais - críticas e pós-críticas - demonstram consciência na seleção dos conteúdos, ao incluírem o exercício de poder em suas discussões. Isso possibilita a ampliação das análises curriculares sob um prisma mais amplo ao englobar a formação da identidade do educando a partir desse tipo de escolhas. Salientando o poder do professor na seleção do currículo, pois ele estará privilegiando um tipo de conhecimento em detrimento de outros, se todo currículo é uma expressão de poder intencional, o papel do professor torna-se mais amplo e cabe a este exercê-lo de maneira mais consciente, analisando as implicações de suas escolhas na formação do aluno. Se ele escolherá um currículo tradicional ou crítico não é a questão mais imediata, o principal é que ele pondere sobre suas escolhas, como afirma Tomaz Tadeu da Silva (2004, p. 150),

[...] depois das teorias críticas e pós-críticas, não podemos mais olhar o currículo com a mesma inocência de antes. 0 currículo tem significados que vão muito além daqueles aos quais as teorias tradicionais nos confirmam. 0 currículo é lugar, espaço, território. 0 currículo é relação de poder. 0 currículo é trajetória, viagem, percurso. 0 currículo é autobiografia, nossa vida, curriculum vitae: no currículo se forja nossa identidade [...]. 
Após as teorias críticas e pós-críticas, o professor não poderá mais promover suas escolhas curriculares de maneira ingênua, ou seja, se antes as teorias tradicionais "facilitavam" a seleção de conhecimentos, atualmente, a responsabilidade pela formação da identidade do educando pertence ao professor.

De forma semelhante, o artigo de André Chervel discute que as disciplinas não constituem saberes acabados e fixos; pelo contrário, são mutáveis de acordo com mudanças sociais ou da própria dinâmica escolar. Dessa forma, as disciplinas fazem parte da face inovadora do universo escolar, porque são afetadas pelas mudanças na sociedade.

As disciplinas são criadas pelo universo escolar, a partir de mecanismos próprios que estão mais relacionados com o ensino e a aprendizagem do que com o conhecimento produzido pela ciência, em outras palavras, o conteúdo escolar é mais influenciado pelas decisões sobre aquilo que é mais fácil compreender do que pela relevância científica.

Segundo Chervel (1990, p. 217), as disciplinas necessitam da consolidação de um grupo que defina os saberes consagrados, ou seja, aqueles que devem estar presentes no currículo, pois afirma que:

É o caso da história, que não soube encontrar ao longo da evolução pedagógica um estatuto disciplinar sólido, ou melhor, encontrou vários, o que vem a dar no mesmo. Segundo Cournot, Langlois e Seignobos denunciaram, no final do século XIX, a falta de tradição pedagógica nesse ensino. A "crise" atual do ensino de história, sucedendo a outras crises, parece confirmar essas análises antigas: 0 desequilibrio interno da disciplina, favorecendo determinado componente às custas de um outro, não permite a ela produzir os efeitos buscados de modo que ela se beneficie, por parte dos alunos, de uma motivação suficiente, seja pelo fato das circunstâncias históricas, seja pelo fato das "qualidades pedagógicas" do mestre.

A discussão de Chervel em torno da ausência de tradição no ensino de história contribui para discutir as condições do ensino de Sociologia. A nossa hipótese é que ausência, intermitência, falta de material, falta de debate são produto de um atraso na sua consolidação no universo escolar, pois a escola não se pronuncia quanto à seleção dos conteúdos mais pertinentes - aqueles que são passíveis de serem ensinados-, porque 0 conjunto de professores está diluído pelas condições de trabalho, atrasando a construção de debates nessa área de conhecimento, dado que não constituem uma "comunidade". Assim, tal ensino ainda está mais ligado à produção acadêmica - relevância do conhecimento científico - na reprodução dos saberes cientificamente consagrados, pois faz-se uso dos mesmos métodos de explicação dos fenômenos sociais na universidade e no ensino médio, enquanto o ensino universitário de matemática mantém afastado das 
pesquisas ao utilizar conhecimentos com tratamento didático, próprios para serem ensinados, para ensino médio.

Tomas Tadeu da Silva e André Chervel contribuem para a proposição de questões referentes ao currículo geral do ensino médio, tais discussões nos levam a compreender que a situação atual do ensino de Sociologia não é privilégio apenas dela, mas de outras "favorecendo determinado componente às custas de um outro". A Sociologia se enquadra no componente desfavorecido, pois tende-se a pensar que seus conteúdos podem ser abarcados por outras disciplinas, assim não haveria a necessidade de mantê-la no currículo.

Retomando o nível disciplinar do currículo, o estudo de Nilson Machado (2002, p. 119) discute a importância das disciplinas, ao afirmar que:

[...] Isoladamente, cada disciplina expressa relativamente pouco e é de interesse apenas de especialistas, no corpo sintético de uma classificação, amparadas em ordenações e posições relativas, expressam seguramente muito mais.

De acordo com Nilson Machado, uma disciplina isolada concentra somente os interesses de peritos por se reduzir a um tipo de linguagem particular, tendendo a produzir conhecimentos especializados para grupos determinados, fechando-se cada vez mais em si mesma. De modo inverso, quando uma disciplina cria posições e ordenações com relatividade produz conhecimentos relacionais e pode se comunicar com outras disciplinas, chegando a ponto de uma disciplina ser reduzida à outra. A questão é analisada por Moraes (2001, p. 11) quando avalia as justificativas dadas pelo governo ao vetar a inclusão de Sociologia como disciplina obrigatória no ensino médio, pois uma das razões seria "Conteúdos já estão incluídos: segundo o governo, ouvindo seus técnicos, os conteúdos de Sociologia já estariam contemplados"

De acordo com o governo, os conteúdos de Sociologia poderiam ser ministrados por outras disciplinas, tornando assim desnecessário incluí-la na grade curricular obrigatória. Nesse caso, o governo despreza as características individuais da disciplina, ao compreender que seu ensino só oferece a veiculação de informações (conteúdos) sem que se possa proporcionar outras possibilidades aos educandos.

Tal discussão estaria no plano da proposta de curso, na medida em que a seleção de uma linguagem especializada ou não independe das decisões externas dirigidas à grade curricular, que pode alterar o número de aulas de cada disciplina ou sua posição, seja na parte obrigatória ou optativa. Essa questão não define a relação que uma disciplina pode estabelecer com as demais, pois não cabe ao professor decidir.

Nas questões específicas do ensino de Sociologia, temos a pesquisa de Simone Meucci que apresenta uma análise elucidativa dos manuais de ensino de Sociologia 
entre os anos 30 e 40 do século XX, discutindo o contexto histórico em que eles foram escritos.

De acordo com Meucci (2000, p. 15),

[...] muitos autores reconheceram que a Sociologia era uma ciência da adaptação social, capaz de investigar acerca da capacidade de adaptação de diferentes agrupamentos humanos a um projeto de constituição da nação".

Hoje não encontramos mais a idéia de constituição de nação, pois o foco de formação foi modificado, os livros apontam a discussão em torno da sociedade brasileira como objetivo principal.

Segundo Meucci (2000, p. 18),

A Sociologia surge no momento em que se queria, a um só tempo, reconhecer a realidade social do país e constituir a nação; em que se formava uma nova percepção da sociedade, do conhecimento e do papel dos intelectuais. Nesse sentido, nossos autores compreenderam que o conhecimento sociológico era a base para a transformação desta realidade e os sociólogos seriam agentes privilegiados para a execução da obra de constituição da nação.

Dessa forma, os manuais de Sociologia do período analisado eram resposta à realidade, ou seja, eles tentavam oferecer explicações para os problemas sociais enfrentados pela sociedade ocidental naquele determinado tempo e contexto sócio-político.

A contribuição de Meucci é pensar em um projeto de constituição de nação presente nos manuais didáticos do início do século XX. Este estudo poderia contribuir para a compreensão das necessidades dos manuais no período citado e ao mesmo tempo, compará-las com as necessidades do mercado editorial de livros didáticos, a partir da análise de alguns livros do final do século XX. Em estudos preliminares, épossível perceber que o mote principal dos manuais no fim do século XX e início do século XXI é a formação da cidadania.

No passado, segundo o estudo de Meucci um dos objetivos do ensino de Sociologia era preparação para a cidadania e hoje a idéia foi mantida em razão da Lei de Diretrizes e Bases da Educação Nacional - LDB - (Lei N 9.394 de 20 de dezembro de 1996), que define:

$\S 1^{\circ}$ Os conteúdos, as metodologias e as formas de avaliação serão organizados de tal forma que ao final do ensino médio o educando demonstre:

III - domínio dos conhecimentos de Filosofia e Sociologia necessários ao exercício da cidadania (BRASIL, 1997, p. 26). 
De acordo com a LDB, o aluno deve apresentar conhecimentos de Sociologia necessários para o exercício da cidadania, porém o documento não é claro quanto à seleção de tais conhecimentos e nem se estes serão apresentados aos educandos em disciplinas específicas.

Moraes (2002, p. 17) discute a presença da formação para a cidadania na legislação brasileira, pois segundo ele:

[...] pensa-se que se revertem todos os processos de exclusão quando se define a educação como espaço de realização da cidadania. Desde já, se percebe que esse objetivo geral em lei (LDB 4024/ 61, 5692/ 71 e 9394/ 96) não tem profundidade, isto é, concretude - não passa de slogan.

As leis confirmam que aeducação como um todo, mas especialmente a Sociologia, deva ser responsável pela formação dos cidadãos, no entanto, tal tarefa não é exclusiva dessa disciplina nem há garantias de que ela possa atingir esse objetivo, pois seu valor poderia ser reduzido ao fornecimento de conhecimentos especializados nas ciências sociais, o que difusamente pode contribuir para aquela formação da cidadania. Desde aquela época, mas com maior ênfase hoje, um "curso de atualidade" não expressa a formação para cidadania. Verificando os atuais livros didáticos, a concepção do estudo da Sociologia como um "curso de atualidade" permanece até hoje. E talvez por isso, as editoras estejam direcionadas para a formação da cidadania com objetivos de consumo.

A pesquisa de Ileizi Silva et al. (2002), tem o objetivo de analisar o debate sobre o ensino de Sociologia, a partir de periódicos escritos entre 1940 e 2001. Os autores selecionaram suas fontes a partir da leitura dos resumos de artigos publicados e analisaram seu conteúdo em relação ao contexto histórico em que foram escritos.

Segundo Ileizi Silva et al. (2002, p. 6),

A partir de 1998, começam a surgir as primeiras propostas de diretrizes e parâmetros para as áreas e disciplinas. 0 pano de fundo tem sido o ensino através de projetos interdisciplinares, que superem 0 paradigma disciplinar. A radicalização dessa idéia e a não compreensão do que seja interdisciplinaridade tem causado o esvaziamento dos conteúdos disciplinares, ou seja, o desprezo pelas disciplinas e pelos conteúdos específicos. Na esteira dessa visão é que se argumenta a não necessidade de inclusão da Sociologia e da Filosofia como disciplinas, mas somente como noções que perpassem outras disciplinas.

A perspectiva da interdisciplinaridade, presente nas Diretrizes Curriculares do ensino médio, causou um enfraquecimento da presença da disciplina. Em oposição, criou-se uma campanha em torno da volta da obrigatoriedade do ensino de Sociologia, 
porque se entendeu que os conteúdos desta disciplina não estavam contemplados em outras disciplinas.

A pesquisa de Ileizi Silva et al. contribuiu para a compreensão do debate em torno do ensino de Sociologia nos periódicos analisados. Dessa forma, foi possível contextualizar a produção acadêmica desta temática, além de refletir sobre a escassez destes estudos.

A obra de Silva et al. não foi a única que analisou as discussões em torno da presença do ensino de Sociologia, Mario Bispo dos Santos em sua dissertação concluiu que a ausência ou a presença da obrigatoriedade da disciplina no Ensino Médio esteve ligada a diferentes questões, e ele afirma que:

parece-nos que a presença ou ausência dessa disciplina esteve sempre relacionado ao contexto político do país, ao grau de mobilização dos movimentos sociais e especialmente à visão dos elaboradores das reformas educacionais no que diz respeito à relação entre ciência, educação e sociedade (SANTOS, 2001, p. 3).

De acordo com Santos, há três questões a serem discutidas: a mobilização dos professores, o contexto político e a atuação dos elaboradores das reformas educacionais. 0 autor debate a mobilização dos professores como forma de promover mudanças na esfera do ensino, para tanto ele analisa as experiências de professores da rede estadual de ensino do Distrito Federal. 0 contexto político foi marcado por uma abertura que promoveu uma maior participação da população na vida pública do país e criou condições para que essa mesma participação fosse incluída em outras esferas, especialmente na educação. E por fim, 0 autor ressalta a participação dos elaboradores das reformas educacionais, que foram pessoas dispostas a promover as mudanças educacionais, seja na formulação das propostas oficiais de ensino seja nos congressos de professores. Essas questões devem ser compreendidas a partir de contextos ideológicos produzidos na esfera educacional.

De acordo com a Proposta Curricular para o Ensino de Sociologia de 1992, a presença de Sociologia em 1983 esteve atrelada a ação dos elaboradores de reformas educacionais, uma vez que eles chamaram os professores a participarem do Congresso de Sociólogos.

Esse processo teve início em 1983 com as lutas desencadeadas pelos professores da rede, associações profissionais e professores das universidades, e que resultou na possibilidade de opção pela inclusão da Sociologia, Psicologia e Filosofia, prevista pela Lei 7.044/82, e sua recomendação explícita na Resolução SE/236/83 (SÃ0 PAUL0, 1992, p. 7).

A partir da Resolução SE/236/83, Sociologia foi recomendada explicitamente 
para integrar a grade curricular das escolas médias, de modo que esta foi resultado da mobilização e atuação dos professores da rede estadual de ensino na luta pela inclusão da Sociologia.

Esta discussão em torno da Resolução citada também está presente em Olavo Machado (1996, p. 14),

A resolução SE-236/83, sobre as diretrizes para a reorganização do ensino de $2^{\circ}$ grau nas escolas da rede estadual paulista, recomendava a inclusão da Sociologia, entre outros componentes diversificados do currículo, visando à "formação do homem crítico e participante", tornando-a matéria optativa nas escolas da rede pública.

Tanto a Proposta de Curricular de 1992, quanto Olavo Machado analisam a importância da Resolução SE-236/83, ao indicarem-na como resultado da mobilização dos professores ou salientarem a inserção da Sociologia nas escolas públicas.

Em outro trabalho, Ileizi Silva (2003,p. 21) fezuma pesquisa importante reunindo e discutindo os trabalhos brasileiros sobre o ensino de Sociologia, e constatou que:

As dissertações de Pacheco filho (1994) e de Meucci (2000) demonstraram que os autores dos primeiros Manuais de Sociologia de 1931 a 1942, defensores do ensino da sociologia na escola secundária e no ensino superior, também associavam 0 ensino de sociologia aos propósitos mais amplos de construção da nação, da democracia, da modernidade, etc. Alguns desses autores eram católicos e acreditavam que a sociologia contribuiria para a formação de cidadãos cristãos, encarregados da missão de transformar o Brasil atrasado em Brasil moderno. Guelfi (2001) fez a mesma constatação em seu estudo. E, Giglio (1999) ressaltou como Florestan Fernandes e Costa e Pinto justificavam o ensino de sociologia nas escolas secundárias. Esses autores acreditavam que ela formaria indivíduos mais racionais, capazes de se apropriar das explicações científicas, compreendendo melhor a realidade social e portanto intervindo com mais consciência. Santos (2002), ao analisar o que os professores de sociologia pensam sobre seu ensino, bem como o conteúdo da reforma da educação de 1997 em diante, constatou as atribuições dadas ao ensino dessa disciplina, persistindo a associação à maior racionalização dos cidadãos e na própria formação do cidadão.

De acordo com o levantamento de Ileizi Silva, cada pesquisador apresentou tipos de trabalhos diversificados com temas relacionados diretamente ao ensino de Sociologia. A partir do resumo, é possível compreender alguns pontos que aproximam as pesquisas citadas, como Pacheco e Meucci, por estarem diretamente relacionados com o ensino, em especial, esta última por desvendar os propósitos de constituição da nação brasileira a partir do ensino de Sociologia. Em outros estudos, a partir de fontes contemporâneas - 
entrevistas com professores - Santos discutiu a formação da cidadania no ensino de Sociologia. Portanto, cada pesquisador desenvolveu pesquisas com diversos materiais: manuais didáticos (Meucci), entrevistas com professores da rede pública (Santos) para entender os objetivos do ensino de Sociologia.

Estas e outras questões em torno do ensino de Sociologia estavam presentes desde o início de minha carreira docente, em que a seleção de um tipo de conhecimento em detrimento de outro definia uma identidade na formação do educando. Em razão da minha experiência como professora de ensino médio, percebi a relevância do problema ao pesquisar sobre trabalhos nessa área e descobrir a ausência de discussão. Como professora, só imaginava os tipos de escolhas de caráter técnico que eu deveria fazer para apresentar os conhecimentos básicos do ensino de Sociologia aos alunos. Durante o meu curso de licenciatura, questionou-se insistentemente os tipos de escolhas que caberiam ao professor, no entanto o desafio real era promovê-las. Para tanto procurei um "plano de aula perfeito", ou seja, aquele que no meu entender promoveria conhecimentos sociológicos e faria sentido para o educando, sem imaginar que outros professores estavam fazendo o mesmo: cada professor de Sociologia também procura ou cria um tipo particular de currículo, muitas vezes, fazendo-o de maneira isolada porque não há muitos professores da referida disciplina em cada unidade escolar, já que o número de aulas é reduzido.

Quanto às questões mais gerais sobre o ensino médio, a jornada de trabalho também constitui um problema para o ensino de Sociologia, na medida em que a jornada integral da rede estadual de ensino compreende trinta e seis aulas semanais, trinta e três em sala de aula com alunos e três coletivas com outros professores; entretanto, a grade curricular atual apresenta somente duas aulas semanais de Sociologia em uma das séries do ensino médio, o que representaria cerca de um terço das classes disponíveis em cada turno; dessa forma, o professor de Sociologia, para obter uma jornada integral, precisaria ministrar aulas em dois ou mais turnos, e, às vezes, em mais de uma escola. Se a jornada integral dificilmente pode ser obtida em uma única escola, então o professor de Sociologia não consegue discutir seu plano de ensino com um colega de área, seu trabalho permanece solitário e nos horários coletivos ele só pode promover trabalhos conjuntos com professores de áreas afins, no melhor dos casos. Se a carga horária de Sociologia fosse maior, uma mesma escola abrigaria mais de um professor e eles poderiam construir um plano de ensino conjunto. Dessa forma, não há espaço para a discussão nem se consolidam grupos de pesquisa no universo escolar. Essa pode ser uma das razões que explicaria a ausência de receptividade dos professores em relação às propostas oficiais de ensino, embora eles vivenciem os problemas educacionais, não são capazes de apresentar soluções próprias, não aceitando reformas exteriores. 
Segundo Bourdieu (LUDKE, 1991, p. 7),

[...] Pessoas da base, professores do primário ou do secundário, por exemplo, dizem às vezes que são os únicos a compreenderem a realidade e que aqueles que querem introduzir reformas (em nome da sociologia, por exemplo) não compreendem nada. Eles estão, ao mesmo tempo, inteiramente certos e inteiramente errados. É preciso escutar essas pessoas, ajudá-las a exprimir sua visão, dando-lhes instrumentos para compreender o que thes acontece e, quando for o caso, para mudar a situação.

Bourdieu aponta para o desencontro entre o discurso dos professores do ensino básico e o dos sociólogos: os primeiros conhecem o universo escolar, mas estão imersos em seus próprios problemas, embora sendo portadores de conhecimento sobre este espaço, mas não são capazes de encontrar soluções, por isso Bourdieu propõe que o sociólogo seja receptivo para compreender tais problemas e propor saída, já que estes profissionais não estão envolvidos, mas têm conhecimento teórico.

0 sociólogo deve agir como parteira. Tem de ser submisso, receptivo, disponível e ao mesmo tempo, ativo, sugestivo, encorajador, tão sábio quanto militante.[...] (LUDKE, 1991, p. 8).

Segundo Bourdieu ainda, a tarefa atribuída ao sociólogo representa grandes desafios, especialmente no que se refere ao fato de ser "submisso, disponível, encorajador" não caracterizariam o trabalho científico, principalmente diante dos professores de ensino básico.

Tanto os sociólogos quanto os professores discutem sobre a mesma realidade, porém não há penetração mútua dos discursos: os professores não aceitam as propostas exteriores porque seriam os únicos conhecedores da realidade escolar e os sociólogos não conseguem escutar de modo adequado os professores do ensino fundamental e médio.

Uma das hipóteses para a pouca receptividade das teorias educacionais no interior da escola seria o tipo de formação dos profissionais, em outras palavras, um dos fatores dos problemas de receptividade poderia ser a formação deficitária dos educadores. Como afirmam Moraes et al. $(2005$, p. 359),

[...] o que falta aos professores é um repertório, mas um repertório que ultrapasse o do aluno: conhecimentos de Artes, de História das Ciências, de Filosofia, informações sobre tecnologias, não só as educacionais. Entendemos que, só assim, a tal da interdisciplinaridade possa ser efetivada. E isso também tem um custo e não pode ser efetivado por professores que mal conseguem se reproduzir como pessoas, quanto mais como profissionais, donde a verdadeira indigência cultural da maioria. 
A formação cultural do professor é precária, o que Moraes et alii chamam de "verdadeira indigência cultural", pois alunos e professores, em geral, não apresentam repertórios diferentes. Assim o educador não estaria preparado para desenvolver trabalhos interdisciplinares, uma vez que sua formação cultural não possibilita a associação dos conteúdos de sua área com outras.

Desse modo, o ensino de Sociologia é influenciado pelas condições do trabalho docente na escola pública que:

Devido às condições precárias do trabalho docente, mormente nas escolas públicas estaduais que não dispõem de coordenadores pedagógicos, nem de nenhuma sorte de orientação voltada para o desempenho docente diário (salvo raríssimas exceções), o profissional conta apenas com sugestões oferecidas pela disciplina 'prática de ensino' do seu tempo de universidade (VIANNA; RIDENTI, 1998, p. 89).

Grande parte dos professores encerra sua formação na graduação universitária e após esta formação inicial, eles não buscam novas fontes de conhecimento que não estejam no interior de sua escola (livros didáticos, por exemplo), alguns buscam cursos de curta duração oferecidos pela Secretaria Estadual de Educação, chamados de 'reciclagem'. Percebemos que os professores da rede pública estadual de São Paulo apresentam problemas de formaçã $0^{4}$ e em razão disso, apresentam dificuldades no cumprimento das atividades exigidas - leitura dos textos obrigatórios, apresentação de semináriose discussões - quando freqüentam os cursos de graduação como alunos especiais. 0 conhecimento dessa atuação deficitária contribui para compreender as atuais condições do ensino, pois muitas vezes, estes professores não conseguem articular as teorias educacionais com os problemas que enfrentam em suas salas de aula. Os problemas podem ocorrer em razão da dificuldade de encontrar cursos fora do horário de trabalho ou a própria resistência quanto à aceitação de idéias exteriores ao universo escolar, ou seja, de origem universitária, na medida em que o diálogo com a universidade foi encerrado na formação inicial, graduação, confirmando Bourdieu.

Um outro problemaé a ausência de discussão, pois hápouquíssimos estudos sobre o ensino de Sociologia, embora a disciplina seja ministrada no nível médio, livros didáticos sejam escritos e estudantes de ciências sociais sejam formados para esse fim,

\footnotetext{
${ }^{4}$ Estas informações foram obtidas durante a monitoria, realizada no Programa de Aperfeiçoamento Estudantil (PAE) da Universidade de São Paulo, na disciplina Metodologia de Ensino em Ciências Sociais I e II - 2004 e 2005 -, na qual tive a oportunidade de observar a participação dos professores da rede pública de ensino que podem fazer algumas disciplinas de graduação como alunos especiais. Grande parte deles procura cursar alguma disciplina com o intuito de ingressar posteriormente no programa de pós-graduação em educação da Universidade de São Paulo.
} 
mas as experiências dessa prática continuam dispersas, fazendo-se, pois, necessária a reunião de informação acerca dessas práticas.

Segundo Ileizi Silva (2003, p. 21),

Ressalto que, com exceção do trabalho de Meucci (2000) e Pacheco Filho (1994), os demais realizaram a história da disciplina sociologia nas escolas secundárias, através de uma análise da história das políticas educacionais, o que implicou na contextualização dos projetos políticos e educacionais em jogo, que atribuíam funções diferenciadas ao ensino de sociologia. [...].

Assim os raros estudos sobre a disciplina Sociologia não discutem diretamente 0 ensino, pois tratam principalmente do histórico de institucionalização da disciplina no Brasil. Esses estudos contribuíram para a compreensão dos contextos político e educacional do período, no entanto, para que a discussão sobre o ensino avance se faz necessário ampliar em número e diversidade as pesquisas em torno da Sociologia, entrando no debate sobre conteúdos, recursos didáticos, metodologias e formação de professores; incluindo aí pesquisas sobre as práticas de ensino.

Além disso, os estudos raramente se comunicam, ficando isolados uns dos outros, o que não permite que a discussão avance nem que os resultados desses estudos sejam incorporados pelas práticas de ensino da disciplina. Isso diferencia o ensino de Sociologia das demais disciplinas, como na Língua Portuguesa em que há muitos estudos e as discussões curriculares progridem de maneira mais linear. Como é possível observar por este fragmento extraído do Parâmetro Curricular Nacional (PCN) de Língua Portuguesa, para $1^{\mathrm{a}}$ a $4^{\mathrm{a}}$ séries do ensino fundamental:

Tem-se observado que a afirmação de que o conhecimento é uma construção do aprendiz vem sendo interpretada de uma maneira espontaneísta, como se fosse possível que os alunos aprendessem os conteúdos escolares simplesmente por serem expostos a eles. Esse tipo de desinformação - que parece acompanhar a emergência de práticas pedagógicas inovadoras - tem assumido formas que acabam por esvaziar a função do professor (BRASIL, 1997, p. 29)

Em uma nota a essa passagem, os autores dizem:

Uma delas é 'agora não é mais para corrigir nada'. Isso não é verdade, a correção é bem-vinda sempre que for informativa. 0 problema é que, para decidir quando e qual correção é informativa, deve-se poder interpretar o erro - o que exige conhecimento nem sempre disponível (BRASIL, 1997, p. 29)

As discussões em torno do ensino de Língua Portuguesa estão mais articuladas, uma vez que o trecho citado demonstra a penetração de outros discursos, como, por 
exemplo o construtivismo denominado de "uma maneira espontaneísta" ou "práticas pedagógicas inovadoras", discutindo questões para além da definição de conteúdos mínimos, porque, possivelmente, tais discussões já tenham alcançado aceitação dos agentes.

A citação de uma concepção espontaneísta faz referência ao construtivismo, ao afirmar que:

[...] a educação do sentido histórico da criança supõe a educação do espírito crítico ou objetivo, a da reciprocidade intelectual e a do senso de relações ou de escalas, nada nos parece mais próprio para determinar a técnica de ensino de história que um estudo psicológico das atitudes espontâneas da criança, por mais ingênuas e negligenciáveis que elas possam parecer de início (CARVALHO, 2001, p. 61).

Nesse trecho, Piaget se refere as atitudes espontâneas das crianças como forma de ensinar História. De modo análogo identificamos a incorporação deste tipo de concepção em outras áreas de conhecimento como na Língua Portuguesa, mesmo que incorporadas de forma questionável, diferente das recomendações de Piaget se considerarmos que tal estratégia surtiria algum efeito em qualquer disciplina. Conforme Carvalho (2001, p. 62),

[...] não é possível, a partir da descrição dessa pretensa natureza do "desenvolvimento espontâneo da noção de história", "deduzir" ou derivar decisões fundamentais sobre os conteúdos, metas e formas de ensino.

De acordo com Carvalho, "o desenvolvimento espontâneo da noção histórica" não ocorreria do modo como Piaget concebia, uma vez que o processo histórico não é algo que possa ser deduzido por haver uma série de fatores a serem analisados no ensino de História. Mediante essas referências poderíamos rediscutir a questão nas demais disciplinas, se para o ensino de História o espontaneísmo é questionável, quiçá nas demais.

Mesmo diante dessas dificuldades, reconhecemos que as discussões educacionais na disciplina Língua Portuguesa estejam mais avançadas, em oposição a Sociologia que ainda discute o estabelecimento de um currículo mínimo. Os educadores em Língua Portuguesa já estabeleceram, ao longo do tempo, um currículo mínimo a ser oferecido na educação básica, e, ainda que discutam a ordenação e a forma como estes devam ser ensinados, eles não estão discutindo mais a relevância dos temas selecionados ou a própria legitimidade da disciplina, tal como ocorre no estado atual de discussão da Sociologia.

0 campo dos estudos sociológicos permanece sem agentes interessados no desenvolvimento de pesquisas sobre o ensino de Sociologia, pois os professores não criam 
nem encontram espaços com esse intuito e os acadêmicos resistem em investir no ensino de Sociologia. Os professores do ensino médio estão mais preocupados em encontrar 0 número de aulas suficientes para completar a jornada integral do que em promover discussões no interior das escolas, em razão das atuais dificuldades impostas pela divisão da grade curricular que privilegia as disciplinas instrumentais Língua Portuguesa, por exemplo com maior número de aulas. No plano acadêmico, estudos sobre o ensino ainda estão em posição subalterna em relação a estudos de ordem teórica; em outras palavras, os estudos educacionais sobre ensino ainda não conquistaram um espaço legítimo no campo científico. Uma das razões seria o abandono desse tema pelos sociólogos, uma vez que eles permitiram que os pedagogos se apropriassem dos estudos educacionais, possivelmente por uma ausência de interesse e a partir disso, a produção acadêmica ficou a cargo de profissionais com outra formação. Então, o que temos são pedagogos estudando sobre questões educacionais de toda ordem, inclusive na área de Sociologia, porém com um viés diverso do sociólogo, podendo desprezar particularidades da disciplina em análises genéricas. Um pedagogo costuma traçar diretrizes gerais para a educação brasileira, que não privilegia a especificidade disciplinar, pois sabemos que, as correntes educacionais atuais primam pela dissolução das disciplinas. Dessa forma, os problemas enfrentados por cada disciplina, muitas vezes, não fazem parte da lista das prioridades dos pedagogos. As análises acerca do ensino de Sociologia ainda não pertencem a uma lista de prioridades da educação brasileira, a questão fica posta em um plano secundário por sociólogos e pedagogos, especialistas em educação. 


\section{REFERÊNCIAS}

BRASIL. Lei de diretrizes e bases da educação nacional: Nova LDB (Lei N 9.394). Rio de Janeiro: Qualitymark, 1997.

BRASIL. Ministério da Educação. Parâmetro Curricular Nacional para ensino fundamental I. Brasília, 1997.

CARVALHO, José Sergio Fonseca de. Construtivismo: uma pedagogia esquecida da escola. Porto Alegre: Artmed, 2001.

CHERVEL, A. História das disciplinas escolares: reflexões sobre um campo de pesquisa. Teoria \& Educação, Porto Alegre, v.2, p 177-229, 1990.

FERNANDES, F. O ensino da Sociologia na Escola Secundária Brasileira. $1^{\circ}$ Dossiê de Ciências Sociais, São Paulo: CEUPES, 1985. Publicado primeiramente em 1955, apresentado em 1954 no I Congresso de Sociólogos.

LUDKE, M. Entrevista com Pierre Bourdieu. Teoria \& Educação, Porto Alegre, n. 3, p.8, 1991.

MACHADO, Nilson J. Educação: projetos e valores. São Paulo: Escrituras, 2002.

MACHADO, Olavo O ensino de ciências sociais na escola média. 1996. Dissertação (Mestrado)

- Faculdade de Educação da Universidade de São Paulo, São Paulo.

MEUCCI, Simone. Institucionalização da Sociologia no Brasil: os primeiros manuais e cursos. 2000. Dissertação (Mestrado) - Universidade Estadual de Campinas.

MORAES, Amaury César et al. Parecer sobre o Parâmetro Curricular Nacional de Ciências Sociais. Brasília: MEC, 2005.

MORAES, Amaury César. As Diretrizes Curriculares Nacionais para os cursos de licenciatura: tentando uma abordagem. In: ENCONTRO ESTADUAL DE COORDENADORES DE CURSOS DE CIÊNCIAS SOCIAIS, 2002, Campinas. Comunicação... Campinas: UNICAMP, 2003. p. 2.

MORAES, Amaury César. Enriquecimento pedagógico ou criticidade. Boletim do Sinsesp, São Paulo, p. 4-5, dez., 2002.

MORAES, Amaury Cesar. O ensino de Ciências Sociais sob novas diretrizes. In: REUNIÃO ANUAL DA ANPOCS, 28., FÓRUM FILOSOFIA E SOCIOLOGIA NO ENSINO MÉDIO: ROMPENDO PRECONCEITOS, 2004, Caxambu. Comunicação... Caxambu, 2004. p. 5.

MORAES, Amaury Cesar. 0 veto: sentido de um gesto. Boletim do Sinsesp, São Paulo, p. 1012, out., 2001.

MORAES, Amaury César. Variações sobre o mesmo tema: presença da sociologia no ensino médio. O Diretor Udemo, São Paulo, p. 17, set., 2002.

SANTOS, Mario B. As representações sociais de ciência e sociologia dos professores de sociologia da rede pública do Distrito Federal. 2001. 169p. Dissertação (Mestrado) Universidade Federal de Brasília, Brasília. 
SÃo PAULO. Secretaria de Educação do Estado. Proposta curricular para o ensino de sociologia de $2^{\circ}$ grau. São Paulo: CENP, 1992.

SILVA, Ileizi L. F. et al. 0 ensino das ciências sociais: mapeamento do debate em periódicos das ciências sociais e da educação de 1940 a 2001. In: CONGRESSO NACIONAL DE SOCIÓLOGOS, 12., 2002, Curitiba. Anais... Curitiba, 2001. p. 6.

SILVA, Ileizi L. F. Por uma sociologia do ensino de sociologia: estudo sobre as dinâmicas regionais da institucionalização nos Sistemas de Ensino (o caso do estado do Paraná 1970-2002). São Paulo, 2003. Texto para exame de qualificação apresentado na Universidade de São Paulo.

SILVA, Tomaz T. da. Documentos de identidade: uma introdução às teorias do currículo. Belo Horizonte: Autêntica, 2004.

VIANNA, C.; RIDENTI, S. Relações de gênero e escola: das diferenças ao preconceito. In: AQUINO, J. G. (Org.). Diferenças e Preconceito na Escola: Alternativas teóricas e práticas. São Paulo: Summus, 1998. p. 89-105. 